could be more generally resorted to for the cure of hæmorrhoids-the actual cautery, which was used by him in the following manner:- "With a pair of large clamp-like forceps, meeting by their flat edges for abont two inches of their blarles, which are here covered over with strong buff leather, which likewise forms an apron of about six inches in diameter, the hæmorrhoidal excrescences are grasped tightly at their base. The leather and forceps are previously wet with cold water, and when the piles are fixed in the manner we have described between the jaws of the forceps, thtir necks or pedicles are partially strangled by means of the pressure thus applied, while the surrounding leather protects the neighbouring parts from the action of the cautery thus applied. A burning iron, somewhat in the shape of a hay.knife, but with a stem twelve inches in length, fastened into a wooden handle, and alto. gether somewhat resembling Mr. Peil's lithotome, is brought to a white heat, and while the bæmorrhoids are fixed as already described, it is quickly applied with a slight sawing motion upon each side of them, and they are thus instantaneously, without hæmorrhage, and with comparatively little pain, removed." (Dublin Quarterly Journal of Medical Science, 1846, vol. ii., p. 563.)

Many years after the above was published in the Dublin Quarterly Jourinal, Mr. Henry Lee read a paper, at the Medical Society of London, recommending the use of a clampforceps in the cure of hæmorrhoids.

I am, Sir, your obedient servant,

March, 1862.

Erinensis Redivivus.

\section{NEW REMEDIES.}

To the Elitor of The LANCET.

SiR,-Allow me, through the medium of your journal, to make a few remarks on a hitherto untried remedy in dysentery, phthisis, and strumons diseases generally-the result of some years' practical observation, both at home and abroad, but more particularly in this country. The remedy I allude to is Lichen Jcelandicus communus, in the form of a syrup (concentrated), as a substitute for, and infinitely more valuable than, the nauseous diug, cod oil -at one time, and even now, so much in vogue. The method of preparing the syrup is as follows:-Take a pound and a half of the moss; soak in hot water, not boiling, for one night only, so as to get rid of grit and sand, and then drain carefully; afterwards boil for two hours, so as to make an infusion, with one quart of water and a pound and a half of sugar added; then strain, add another quart of water, and boil for half an hour, thickening with a slight further addition of sugar; and when nearly cold, add four ounces of brandy or any other spirit. It is then ready for use, and the doses given are similar to those of the cod-liver oil, but with much more promising resulte.

I am, Sir, yours respectfully,

John Mitcheli, L.R.C.S.E.

Lancaster Infirmary, March 4th, 1862

\section{ON THE CONDITION OF THE MOUTH IN IDIOCY.}

To the Elitor of THE LANCET.

SIR,-In some recent numbers of your journal there is a correspondence concerning that "arching of the palate" so commonly noticed amongst idiots. Allow me to say that when the Asylum for Idiots was in its infancy I pointed out the peculiarity in question to Drs. Conolly and Little, and that the resident medical officer, Dr. Maxwell, always examined and measured the palate of every patient in the Asylum. Dis. regarding any question as to the originality of the observation, would it not be better to consider the cause of the malformation? I tbink it clearly depends upon the imperfect function of the sphenoid bone, the growth of which being arrested, the vomer does not receive that impulse which should compel it, in its turn, to push downwards and forwards the palatine processes of the superior maxillary bones. Does this arrest of development of the sphenoid depend upon a want of local nutrition, or is it the result of that deficiency in the great nervous centre with which these unfortunates are afflicted? Would it not be interesting to know whether the palates of the deaf-dumb present any analogous deformity? Here, where I am somewhat bookless, I have few authorities to consult, and can only offer a suggestion.

Your review of Dr. Pietra-Santa's work upon the Climate of Algiers would hardly seem to be complete without a reference to the admirable work of our countryman, Dr. A. Mitchell ; it is quite exhaustive, and ranks so high that it has been translated into French by $\mathrm{my}$ talented and courteous confrère, Dr. A. Bertherand, the Medical Director-General of the Army of Algiers. I could endorse all that has been writien of the beauty and salubrity of our climate, but for obvious reasons $I$ refrain.

I may, perhaps, $\grave{a}$ propos of "New Remedies," say that have a gentleman under my care who speaks in the highest terms of the Datura tatula. He is sixty years of age, and is subject to spasmodic asthma, which compels him yearly to winter abroad. He has tried doctors and drugs acl nauseam, and alone obtains relief from the plant in question. He smokes it, mixed with camphor, either in a pipe or in the form of a cigar; and tells me, moreover, that the Datura stramonium gives him no relief.

Apologizing for so desultory a letter, I am, Sir, yours, \&c.,

Rue Napoléon, Algiers, Feb. 21st, 1862. Thos. Callaway.

\section{CONSERVATIVE SURGRRY. To the Editor of The Lancet.}

Srr,-I beg to send you the following case, which perhaps you may think worthy of insertion:-

J. C- aged eight years, came to me on the 27 th December last, with a wound extending in to the metacarpo-phalangeal articulation of the left thumb, which he had received that morning from a hatchet with which another boy was chopping wood. The ligaments and the whole of the muscles of the thumb, with the exception of the flexor muscles, were severed, but the cartilages covering the ends of the bones were uninjured. Wishing, if possible, to save the thumb, I replaced it in its proper position, stitched up the wound, and strapped it firmly with strips of plaster, plicing a bandage over all; and directed the boy to remain in bed and keep his hand at perfect rest. On removing the dressings three days afterwards, I found the wound healing by the first intention, and looking as well as could be wished. At the time I am now writing (Feb. 25th) the wound has completely healed. There is perfect motion in the joint, and the boy is able to flex his thumb and grasp firmly any object in his hand, though, from the extensor muscles being severed, he is not able to extend it himself.
Chudleigh, Devonshire, Feb. 1862 .
Gramam Capter, M.D.

\section{PARISIAN MEDICAL INTELLIGENCT.}

(FROM OUR SPECIAL CORRESPONDENT.)

THE yearly meeting of the Society of Acclimatization was held last week at the Hotel de Ville. The attendance was very numerous, and the presence of Prince Napoleon, as well as of several members of the Corps Diplomatique, combinad to give an official gravity to the proceedings. Amongst the most interesting of the speeches was an eloquent eulogium on the late Geoffroy de St. Hilaire, delivered by M. Drouyn de l'Huys, for some time representative of the Imperial Government in London. The Society of Acclimatization owes a great measure of its success and prosperity to the late director, who for the space of eight years had most zealously devoted his time and energy to its advancement. A tribute was therefore due to his memory, and the ex-plenipotentiary edified his andience by the display of a whole bouquet of flowers, culled most certainly from no protocollic parterre. Here is the last sprig from the bunch:- " "It was undoubtedly the love of his fellows which led Geoffroy St. Hilaire into the path in which we have followed him; we owe it to his memory to continue his work. May the master minds of science march at onr head, and pursue through his initiative that work of ages which brings the intelligence of man into contact with the Eteraal Truth! Science is that mysterious ladder on which Jacol saw, while dreaming, angels ascending and descending to convey heavenwards the aspira. tions of earth, and to convey back to earth the benedictions of Heaven." This sounds very like an attempt to acclimatize a bit of the Koran, or else a new reading of the Pentateuch, which might fitly figure in an appendix to the next edition of " Essays and Reviews." It is anyhow fortunate for the orator that the 